\title{
AN INTERESTING COPY OF WIEDEMANN'S DIPTERA EXOTICA
}

About 1893 I purchased a copy of Wiedemann's "Diptera Exotica" from a European dealer. I did not examine it carefully at the time, and it was not until about 1915 that I discovered that pages 39 to 42 were missing. Comparing it with the copy in the Boston Society of Natural History, I find that the title page is quite different and reads as follows:

\section{DIPTERA ExoTICA}

Sectio I. antennis multiarticulatis

Munus Decani Fac. Med. deponens edidit

Dr.C.R. G. Wiedemann

Kiliæ 1820

Following page 38 instead of page 39 is the usual titlepage of the work:

C. R. G. WIEDEMANN

Med. Doctoris, in Acad. Kiliensi Prof. Med. P. O.

DiPTERA ExoticA

Pars I

Tabulis Fneis Duabus

Kiliæ 1821 
Following this and in place of page 41 is the sub-title page

Dipterorum exoticorum

Sectio II

Antennis parumarticulatis

which is placed in front of page 43, "Supplementum ad sectionem I." It should have been placed in front of page 45, "Section II. Antennis parumarticulatis."

The text on page 38 ends some distance from the bottom, with a - Evidently whoever compiled the book lacked pages 39-42, and, thinking that the two leaves containing the title page of 1821 and the sub-title of Sectio II, filled the gap, bound them accordingly. All references to this work bear the date 1821. However, from the copy here described, it is very evident that the first 38 pages and probably pages $39-42$, and the supplement to Section I, pages 43 and 44, were published in 1820 and not in 1821 . Pars I on the title page of 1821 would indicate that the author contemplated other volumes.

It would be of interest to know if there are any other copies giving 1820 as the date of publication of the first section. This copy has been presented to the library of the Boston Society of Natural History.

Charles W. Johnson. 

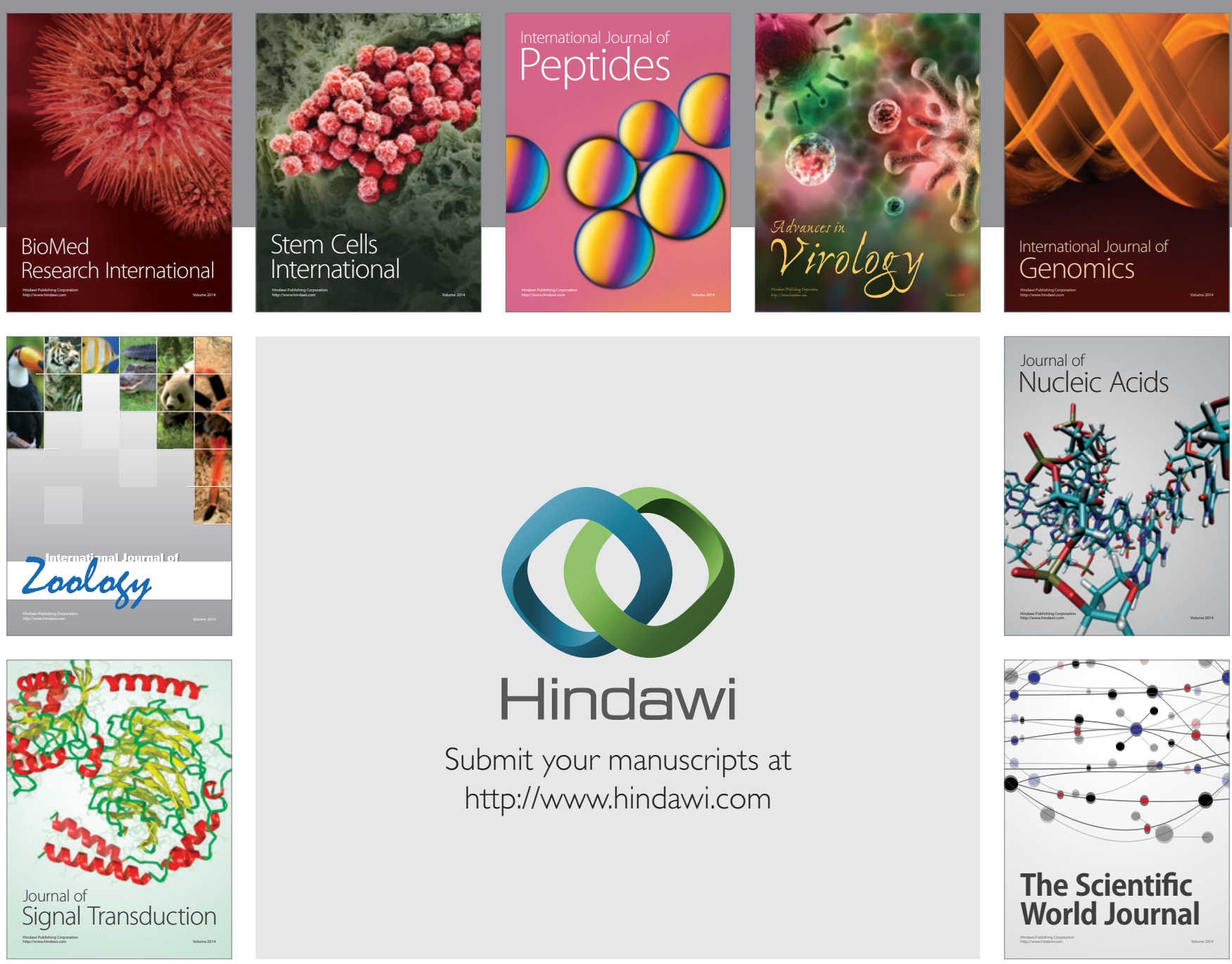

Submit your manuscripts at

http://www.hindawi.com
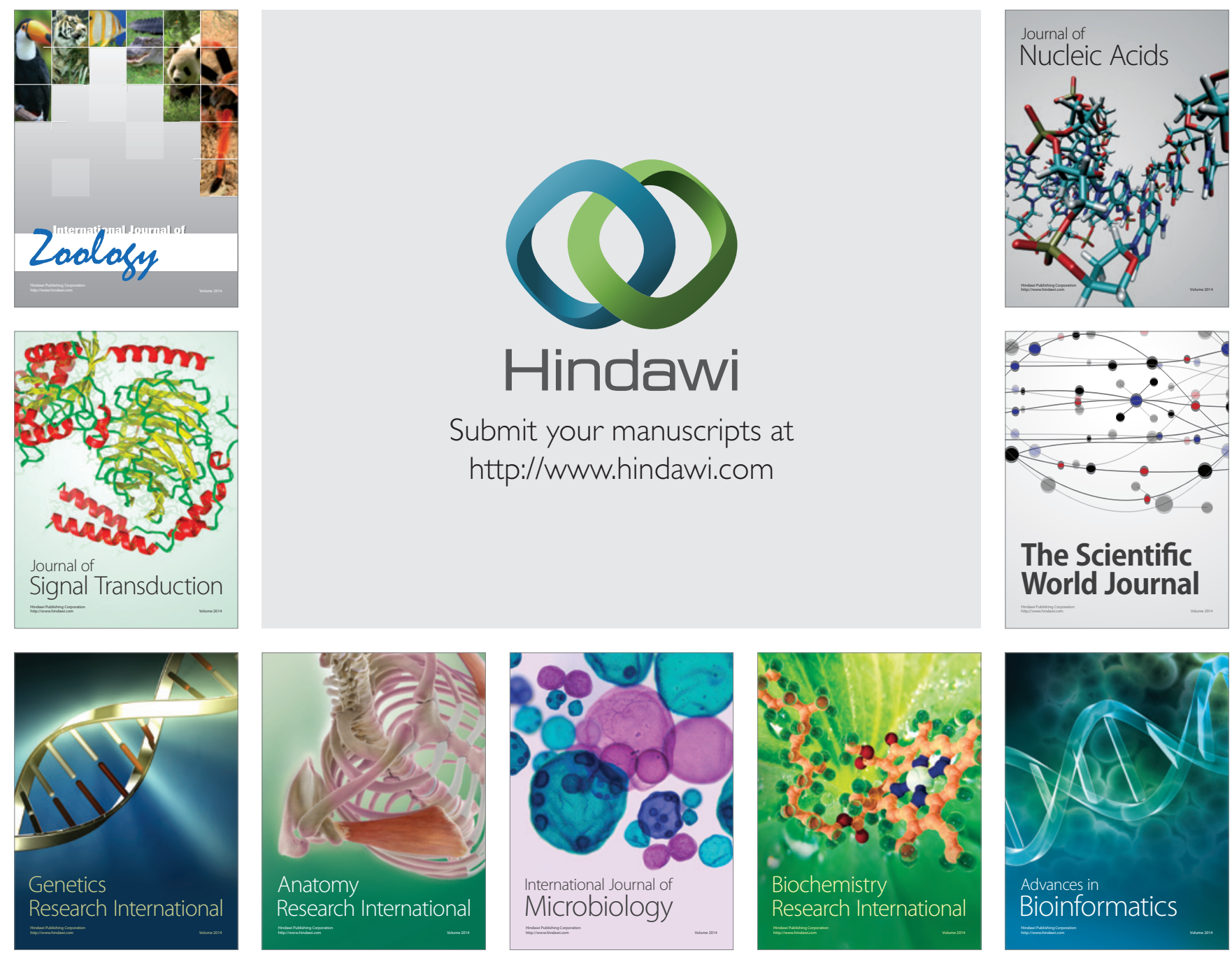

The Scientific World Journal
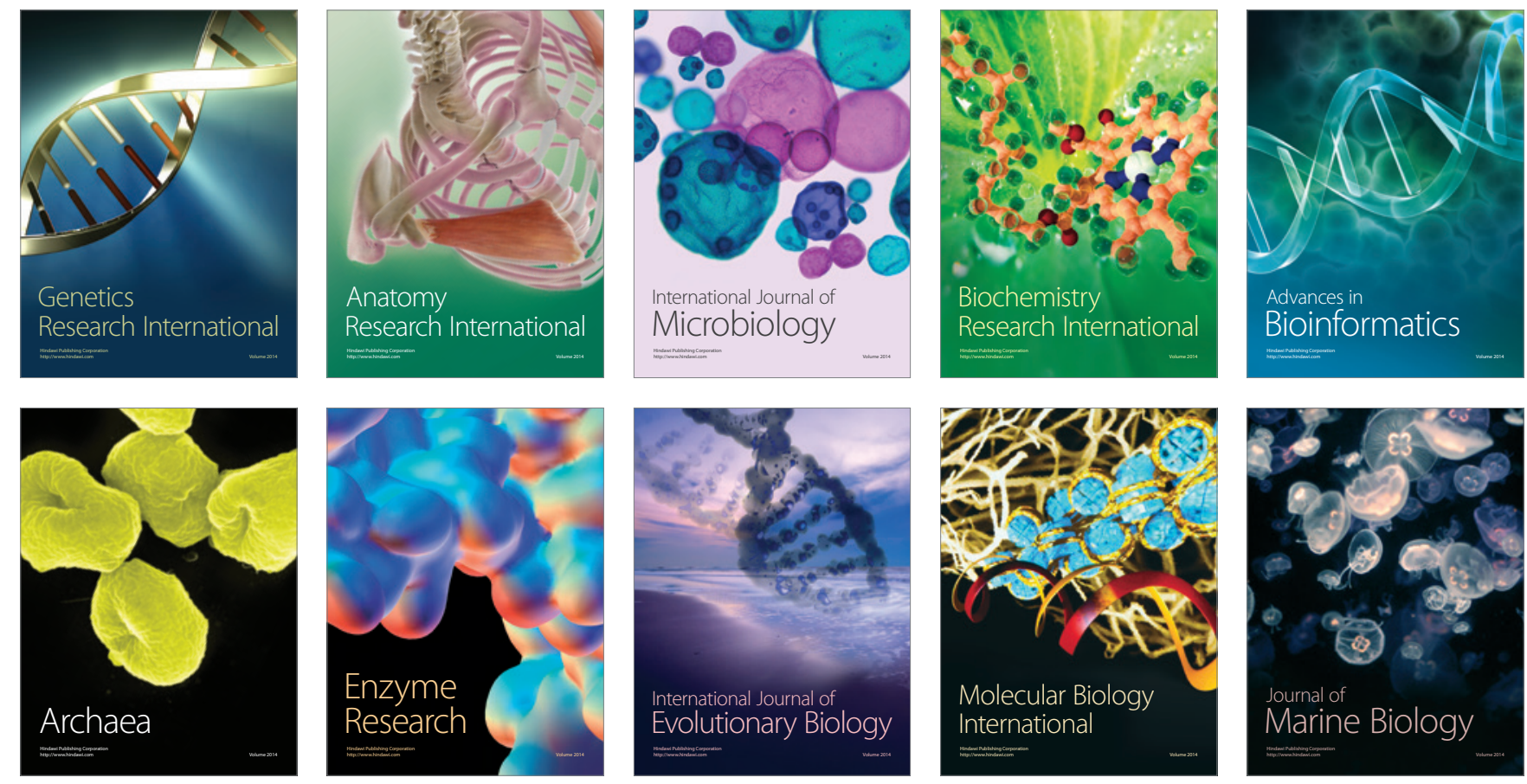